\title{
Reusability of Iron sludge as an Iron source for Fenton-type process*
}

\author{
Jing Zhang ${ }^{\dagger}$ \\ Key Laboratory of Integrated Regulation and \\ Resource Development on Shallow Lakes of Ministry of Education, \\ College of Environment, Hohai University, \\ Nanjing, 210098, China \\ ${ }^{\dagger}$ E-mail: zhang_jing@hhu.edu.cn \\ www.hhu.edu.cn
}

\begin{abstract}
As one of the hazardous solid wastes, iron sludge has received considerable and increasing attention for its potential damage to the environment. Thus this paper reports the reusability of iron sludge for a Fenton-type process. However, the slow transformation of $\mathrm{Fe}(\mathrm{III}) / \mathrm{Fe}$ (II) limits its repetitive and widespread application. Hence, hydroxylamine (HA), a common reducing agent, was introduced to iron-sludge/ $\mathrm{H}_{2} \mathrm{O}_{2}$ system to accelerate the conversion of $\mathrm{Fe}(\mathrm{III}) / \mathrm{Fe}$ (II). With the addition of $\mathrm{HA}$, orange $\mathrm{G}$ (OG) degradation was largely increased at $\mathrm{pH} 2.0-9.0$, and the generation of hydroxylradicals was significantly promoted. It was surprised to find that the catalytic ability of iron sludge maintained constantly in the ten consecutive runs with $100 \%$ iron recovery. Thus the present study provides a promising way to reuse iron sludge for the rapid degradation of refractory organics and dispose the solid iron-based wastes.
\end{abstract}

Keywords: Iron sludge; Fenton; $\mathrm{NH}_{2} \mathrm{OH}$; Hydroxyl radical; Heterogeneous catalysis

\section{Introduction}

Fenton process has been extensively and successfully studied for the effective treatment of industrial wastewater[1]. However, it has a few significant disadvantages: (i) handling dangerous $\mathrm{H}_{2} \mathrm{O}_{2}$ and (ii) high costs of disposing iron sludge. To minimize this disposal, two approaches have been discussed: (a) development of heterogeneous catalysts and (b) reuse of iron sludge. In the former, the catalytic activity of heterogeneous catalysts usually deteriorates with the repeated use of the catalysts because of the leaching of active iron or the decay of active catalytic sites. In the latter, iron sludge is reused as a coagulant for water treatment and as an iron source for Fenton reaction. The input of

\footnotetext{
* This work is supported by the National Natural Science Foundation (51508152), Natural Science Foundation of Jiangsu Province (BK20150812), the China Postdoctoral Science Foundation (2015M571660), the Fundamental Research Funds for the Central Universities (2014B12614) and the Priority Academic Program Development of Jiangsu Higher Education Institutions.
} 
regenerated $\mathrm{Fe}^{3+}$ to the classic Fenton reactor after re-dissolution of iron sludge by acid is simple but $\mathrm{Fe}^{3+}$ must be reduced to $\mathrm{Fe}^{2+}$ by $\mathrm{H}_{2} \mathrm{O}_{2}$ in the reactor, resulting in an increasing chemical cost of $\mathrm{H}_{2} \mathrm{O}_{2}$. Kavitha and Palanivelu [2]recycled iron sludge for the classic Fenton process after sludge re-dissolution through the addition of acid and $\mathrm{HA}$, in which $\mathrm{Fe}^{3+}$ ions in the sludge are reduced to $\mathrm{Fe}^{2+}$ ions by reaction with $\mathrm{HA}$. But can the iron sludge used in the solid form? What is its performance in Fenton process? What is the role of HA in Fenton process?

Therefore, solid iron sludge was introduced into Fenton as an iron source in this paper to (i) explore the role of HA, (ii) evaluate the effects of HA and $\mathrm{H}_{2} \mathrm{O}_{2}$ dosage, and initial $\mathrm{pH}$ on the performance of $\mathrm{HA} /$ Fenton, and (iii) examine the stability of iron sludge in consecutive runs.

\section{Methods and Materials}

\subsection{Materials}

Hydrogen peroxide (30\%), hydroxylamine $\left(\mathrm{NH}_{2} \mathrm{OH}, 99.9 \%\right)$, orange $\mathrm{G}$ (OG, 99.5\%) and Tert-butyl alcohol (TBA)were of analytical reagent grade. 5,5dimethyl-1-pyrolin-N-oxide (DMPO) were of ACS reagent grade and supplied by J\&K Chemical. The iron sludge was obtained from a typical Fenton process.

\subsection{Experimental procedure}

All experiments were performed in $500 \mathrm{~mL}$ borosilicate glass jars with a constant stirring rate at $25^{\circ} \mathrm{C}$. Each $500 \mathrm{~mL}$ reaction solution with desired concentrations of $\mathrm{OG}$, iron sludge and $\mathrm{HA}$, was prepared with ultrapure water and adjusted to the desired $\mathrm{pH}$. The desired $\mathrm{H}_{2} \mathrm{O}_{2}$ dosage was then added to start the reaction. Samples were withdrawn at predetermined time intervals and quenched with excess pure TBA before analysis. The OG was quantified with an UV-vis spectrometer at $478 \mathrm{~nm}$ (Jingke, UV760CRT).

\section{Results and Discussion}

\subsection{Role of $\mathrm{HA}$}

The removal of $\mathrm{OG}$ by $\mathrm{H}_{2} \mathrm{O}_{2}$ alone and $\mathrm{HA} / \mathrm{H}_{2} \mathrm{O}_{2}$ was negligible and that by iron sludge was less than $18 \%$ in 60 min (data not shown). As can be seen in Figure 1(a), less than $20.4 \%$ of OG was degraded in 60 min by Fenton process. Such low degradation efficiency in Fenton process could be interpreted with the limited $\mathrm{Fe}$ (II) sites on iron sludge and the slow transformation from $\mathrm{Fe}$ (III) to $\mathrm{Fe}(\mathrm{II})$. Surprisingly, with the addition of $10 \mathrm{mM} \mathrm{HA}$, more than $99 \%$ of OG was 
degraded in 60 min. It could be inferred that the addition of HA into Fenton process might greatly accelerate the cycle of $\mathrm{Fe}(\mathrm{III}) / \mathrm{Fe}(\mathrm{II})$ and the generation of reactive radicals [3].
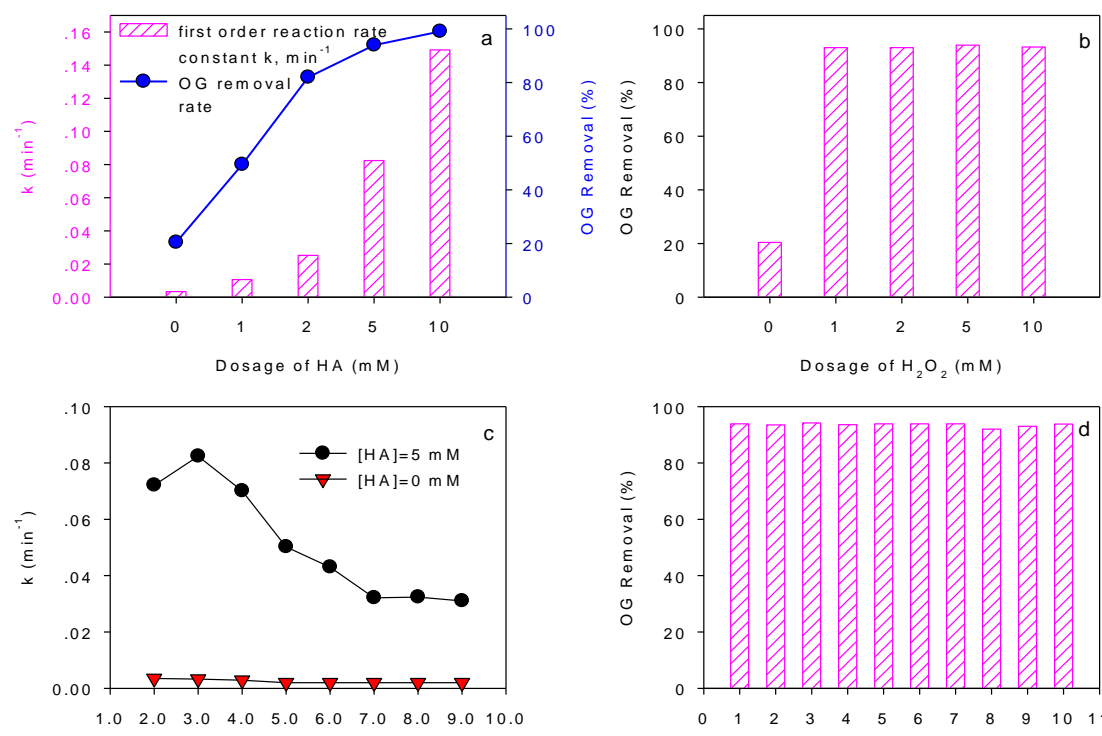

$\mathrm{pH}$

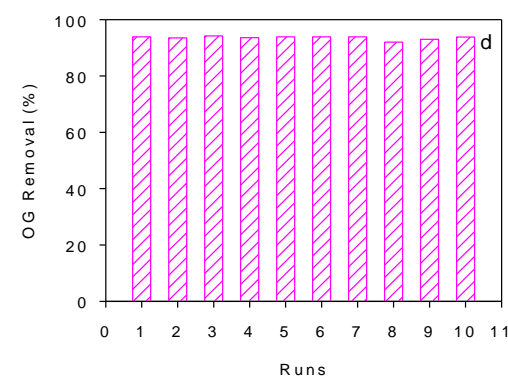

Fig. 1. Effects of (a) HA dosage, (b) $\mathrm{H}_{2} \mathrm{O}_{2}$ dosage, and (c) $\mathrm{pH}$ on the degradation of OG by Fenton process; (d) stability of iron sludge in ten consecutive runs. Reaction conditions: (a) $[\mathrm{OG}]=0.1 \mathrm{mM}$, $\left[\mathrm{H}_{2} \mathrm{O}_{2}\right]=5.0 \mathrm{mM}$, [iron sludge $]=0.1 \mathrm{~g} \mathrm{~L}^{-1}, \mathrm{pH}=3.0,25{ }^{\circ} \mathrm{C}$; (b) $[\mathrm{OG}]=0.1 \mathrm{mM},[\mathrm{HA}]=5.0 \mathrm{mM}$, [iron sludge $]=0.1 \mathrm{~g} \mathrm{~L}^{-1}, \mathrm{pH}=3.0,25^{\circ} \mathrm{C}$; (c) $[\mathrm{OG}]=0.1 \mathrm{mM},\left[\mathrm{H}_{2} \mathrm{O}_{2}\right]=5.0 \mathrm{mM}$, [iron sludge] $=0.1 \mathrm{~g} \mathrm{~L}^{-1}, 25^{\circ} \mathrm{C}$; (d) $[\mathrm{OG}]=0.1 \mathrm{mM},\left[\mathrm{H}_{2} \mathrm{O}_{2}\right]=5.0 \mathrm{mM},[\mathrm{HA}]=5 \mathrm{mM}$, [iron sludge] $=0.1 \mathrm{~g} \mathrm{~L}^{-1}, \mathrm{pH}=3.0,25^{\circ} \mathrm{C}$;. Reaction time is $60 \mathrm{~min}$ for all the experiments.

\subsection{Effect of $\mathrm{HA}$ and $\mathrm{H}_{2} \mathrm{O}_{2}$ dosage}

As shown in Figure 1(a), increased degradation of OG was observed with increasing HA concentration from 1 to $10 \mathrm{mM}$. It should be noted that HA mainly existed in the form of $\mathrm{NH}_{3} \mathrm{OH}^{+}$at $\mathrm{pH} 3.0$ with $\mathrm{pK}_{\mathrm{a} 1}=5.96$. The degradation of $\mathrm{OG}$ was actually regulated by $\mathrm{NH}_{3} \mathrm{OH}^{+}$with the addition of $\mathrm{HA}$ into Fenton process. Although increased $\mathrm{NH}_{3} \mathrm{OH}^{+}$concentration could accelerate the conversion of $\mathrm{Fe}(\mathrm{III}) / \mathrm{Fe}(\mathrm{II})$, the reasonable amount of generated ROS might be quenched by excess $\mathrm{NH}_{3} \mathrm{OH}^{+}\left(\mathrm{k}<5.0 \times 10^{8} \mathrm{M}^{-1} \mathrm{~s}^{-1}\right.$ for $\left.\cdot \mathrm{OH}[4]\right)$.

The effect of variable $\mathrm{H}_{2} \mathrm{O}_{2}$ concentration on the degradation of $\mathrm{OG}$ was studied in HA/Fenton process, as shown in Figure 1(b). The increased dosage of $\mathrm{H}_{2} \mathrm{O}_{2}$ from 1 to $10 \mathrm{mM}$ had no effect on the kinetics of $\mathrm{OG}$ degradation, which indicated that the availability of $\mathrm{H}_{2} \mathrm{O}_{2}$ was not the limiting factor controlling the yield of radicals. 


\subsection{Effect of $p H$}

As shown in Figure 1(c), OG degradation by Fenton or HA/Fenton process exhibited strong $\mathrm{pH}$ dependent. Without $\mathrm{HA}$, the apparent first-order rate constant $\left(\mathrm{k}, \mathrm{min}^{-1}\right)$ decreased linearly from $3.50 \times 10^{-3}$ to $1.99 \times 10^{-3} \mathrm{~min}^{-1}$ as $\mathrm{pH}$ increased from 2.0 to 9.0, while the addition of HA greatly improved OG removal. With initial $\mathrm{pH}$ increasing from 2.0 to 3.0 in the presence of $\mathrm{HA}$, OG removal was promoted due to the formation of $\mathrm{Fe}(\mathrm{OH})_{2}$, which has been reported to be more reactive than $\mathrm{Fe}(\mathrm{II})$ ions due to the presence of $-\mathrm{OH}$ groups [5]. As $\mathrm{pH}$ increased from 3.0 to 9.0, the degradation of OG was sharply dropped from $8.24 \times 10^{-2}$ to $3.10 \times 10^{-2} \mathrm{~min}^{-1}$. This can be attributed to the species distribution of $\mathrm{HA}$ at different $\mathrm{pH}$. As $\mathrm{pH}$ increased from 3.0 to 9.0, the fraction of $\mathrm{NH}_{2} \mathrm{OH}$ gradually becomes the dominant existing form of HA. Hence, a considerable amount of generated radicals would be consumed by HA at near neutral $\mathrm{pH}\left(9.5 \times 10^{9} \mathrm{M}^{-1} \mathrm{~s}^{-1}\right.$ for $\left.\bullet \mathrm{OH}[4]\right)$.

\subsection{Stability of iron sludge}

The effect of HA on the stability of iron sludge was investigated by reusing it in ten successive runs under the same reaction conditions and the results are shown in Figure 1(d). OG was totally decomposed with $100 \%$ iron recovery during the ten runs due to the presence of HA, indicating the regeneration of $\mathrm{Fe}$ (II) sites by HA.

\section{Conclusion}

The applicability of catalytic treatment technologies for azo dye treatment was evaluated by HA enhanced Fenton process. The addition of HA into Fenton process greatly accelerated the cycle of $\mathrm{Fe}(\mathrm{III}) / \mathrm{Fe}$ (II) and the generation of reactive $\cdot \mathrm{OH}$. The stability of iron sludge was satisfied in $\mathrm{HA} /$ Fenton process with no activity loss in the consecutive runs.

\section{References}

1. P.Bautista, A. F.Mohedano, J. A.Casas, et al. An overview of the application of Fenton oxidation to industrial wastewaters treatment. J. Chem. Tech. Biotech., 83, (10), 1323-1338, (2008).

2. V.Kavitha, K.Palanivelu. The role of ferrous ion in Fenton and photoFenton processes for the degradation of phenol. Chemosphere, 55, (9), 1235-1243, (2004).

3. L. W.Chen, J.Ma, X. C.Li, et al. Strong Enhancement on Fenton Oxidation by Addition of Hydroxylamine to Accelerate the Ferric and Ferrous Iron Cycles. Environ. Sci. Tech., 45, (9), 3925-3930, (2011). 
4. G. V.Buxton, C. L.Greenstock,W. P.Helman, et al. Critical review of rate constants for reactions of hydrated electrons, hydrogen atoms and hydroxyl radicals $\left(\cdot \mathrm{OH} / \bullet \mathrm{O}^{-}\right)$in aqueous solution. J. Phys. Chem. Ref. Data, 17, (2), 513-886, (1988).

5. J. J. Pignatello, E. Oliveros and A. MacKay, Advanced oxidation processes for organic contaminant destruction based on the Fenton reaction and related chemistry. Crit. Rev. Environ. Sci. Technol., 36, 1-84, (2006). 